\title{
Evaluation of Tranexamic Acid in Bleeding Control in Primary Total Knee Arthroplasty
}

\author{
Max Rogério Freitas Ramos ${ }^{1 *}$, Leonardo Antunes Bellot de Souza ${ }^{2}$, Rafael Gouvêa de Moraes \\ Vivas $^{2}$, Murilo Nogueira de Oliveira ${ }^{2}$ and Mark de Melo Ramos ${ }^{3}$ \\ ${ }^{1}$ Associate Professor of Orthopedics and Traumatology, Federal University of the Rio de Janeiro State UNIRIO, Head of \\ Orthopedic Clinics at Gaffrée Guinle University Hospital HUGG, Brazil
}

${ }^{2}$ Orthopaedic Specialist by Federal University of the State of Rio de Janeiro UNIRIO, Brazil

${ }^{3}$ Medicine Student in Estadual University of the Rio de Janeiro UERJ, Brazil

*Corresponding author: Max Rogério Freitas Ramos, Associate Professor of Orthopedics and Traumatology, Federal University of the Rio de Janeiro State UNIRIO, Head of Orthopedic Clinics at Gaffrée Guinle University Hospital HUGG, Brazil

\section{ARTICLE INFO}

Received: 豐 August 12, 2020

Published: 陆 August 27, 2020

Citation: Max Rogério FR, Leonardo Antunes Bellot de S, Rafael Gouvêa de MV, Murilo Nogueira de 0, Mark de Melo R. Evaluation of Tranexamic Acid in Bleeding Control in Primary Total Knee Arthroplasty. Biomed J Sci \& Tech Res 29(5)-2020. BJSTR. MS.ID.004861.

Keywords: Tranexamic Acid; Primary Total Knee Arthroplasty; Bleeding

Abbreviations: ATX: Tranexamic Acid; TKA: Total Knee Arthroplasty; T-PA: Tissue Plasminogen Activator

\section{ABSTRACT}

Objective: To evaluate the control of bleeding with the use of tranexamic acid (ATX), administering a single dose of venous tranexamic acid $20 \mathrm{mg}$ per $\mathrm{kg}$ of weight after anesthetic induction in patients undergoing primary total knee arthroplasty.

Methods: This prospective cohort study evaluated 40 patients with tricompartmental gonarthrosis from December 2018 to December 2019. Of these only 20 used ATX and were included in these group. The others are related in the control group. Inclusion criteria were idiopathic gonarthrosis, age between 53 and 65 years, aligned lower limb axis, body mass index less than $35 \mathrm{~kg} / \mathrm{m} 2$ and joint stability. In order to characterize the aligned lower limb, the pre-operative radiological angle measurement was used, considering the aligned limb measured between $7^{\circ}$ of varus to $7^{\circ}$ of knee valgus. Exclusion criteria were non-idiopathic gonarthrosis, age less than 53 years and over 65, lower limb deformity, body mass index greater than $35 \mathrm{~kg} / \mathrm{m} 2$ and joint instability. We compared the mean per operative and post-operative bleeding of both group sand evaluated the effectiveness of ATX in reducing bleeding. Perioperative control was accounted for through the aspirator collectors during the surgery and the bleeding absorbed by the surgical compresses. Postoperative control was assessed by suction drainage debit in the first 48 postoperative hours. We also evaluated the need for blood transfusion between the groups.

Results: The variables investigated in the study: Weight of Dirty Compresses, Collec to rand Pre Bleeding, Post Bleeding and Total Bleeding presented statistically significant values, at the $5 \%$ significance level they rejected the hypothesis that the Control and Test groups had the same bleeding. With this we can say that at a level of $5 \%$ of significance the drug Transamin has effect in reducing the variables that represent the bleeding of patients, except the variable Quantity of Dirty Compresses.

Conclusion: The use of intravenous ATX was effective in reducing bleeding in patients undergoing primary total knee arthroplasty. 


\section{Introduction}

Total knee arthroplasty (TKA) has been more prevalent due to the increase in life expectancy and is already one of the most common elective procedures performed in the United States. Considering TKA to be a major surgery and predicting blood loss, the need for blood transfusion becomes a reality in some settings. Both allogeneic transfusion and blood loss can potentially result in substantial increases in costs and significant complications such as postoperative infection, delayed physical recovery, increased hospital stay and increased mortality [1]. Peroperative blood loss can vary from $300 \mathrm{ml}$ to $2000 \mathrm{ml}$ in primary TKA procedures $[2,3]$. These complications may be more evident in patients with pre-existing medical comorbidities, including degree of deformity, heart, lung, kidney disease and surgical time $[4,5]$.

Although there is a very large number of rigorous tests, blood transfusion causes significant inherent risks including hemolytic reactions, inflammatory tissue damage, infection, among other blood-borne diseases, as well as the immune modulation caused by allogeneic transfusion, contamination and immunological reactions $[6,7]$. In view of the higher financial cost and these possible complications and adverse events associated with blood loss and blood transfusion, it is necessary to investigate and discover strategies to reduce bleeding in TKA. ATX is an antifibrinolytic, inhibits the dissolution of clots by blocking the formation of plasma by not activating the coagulation cascade, reducing the intensity and risks of bleeding [8-10]. The objective of this study was to evaluate the influence of ATX in reducing bleeding in primary knee total arthroplasty surgeries and to evaluate the decrease in the need for blood transfusion.

\section{Methods}

It is a prospective cohort where 40 patients were evaluated, from December 2018 to December 2019, with gonartrosetri compartmental. The work was approved by the Research Ethics Committee of the Center for Biological and Health Sciences at the Federal University of the State of Rio de Janeiro (UNIRIO). CAAE 80969517.0.0000.5258. Inclusion criteria were idiopathic gonarthrosis, age between 53 to 65 years, aligned lower limb axis and body mass index less than $35 \mathrm{~kg} / \mathrm{m}^{2}$ and joint stability. The exclusion criteria were non-idiopathic gonarthrosis, age less than 53 years and more than 65 , deformity of the lower limb and body mass index greater than $35 \mathrm{~kg} / \mathrm{m}^{2}$ and joint instability. To characterize the aligned lower limb, we used the measurement of the preoperative radiological angle, considering the limb aligned between $7^{\circ}$ of Varus and $7^{\circ}$ of valgus of the knee. The perioperative bleeding estimated in the study was that counted in the surgical site aspirators during the surgery plus the bleeding absorbed by the surgical compresses.

Postoperative bleeding was also considered and estimated by the flow of vacuum drains installed during the first 48 hours after surgery. Only one team participated in the surgery of the selected patients. The surgical technique involved a cutaneous incision in the knee midline, followed by soft tissue dissection and sub vastus medial patellar arthrotomy, known as Southern, with joint debridement, soft tissue balance followed by femoral, tibial and patellar cuts. Hemostasis care was observed. No pneumatic tourniquet was used. Vacuum suction drains were positioned to allow adequate drainage of the surgical wound in the postoperative period for 48 hours. Tranexamic acid was used in each patient after anesthetic induction, intravenously, in a single dose $(20 \mathrm{mg}$ per $\mathrm{kg}$ of weight). Patients who met the selection criteria were divided into two groups. In group A (test), with 20 patients, $20 \mathrm{mg}$ per $\mathrm{kg}$ of weight, intravenous, of ATX was administered after anesthetic induction. In group B (control), with 20 patients, ATX was not administered.

The patients involved in the study remained hospitalized for 48 hours postoperatively, in order to identify possible complications related to the use of the drug, especially those resulting from thromboembolic events, such as venous thrombosis, pulmonary embolism, arterial occlusions, renal failure, etc. After this period, we started periodic outpatient monitoring. The results were expressed as means. For comparisons, Student's t-test or Mann-Whitney test was used, when appropriate. The statistically significant results were accepted with $\mathrm{p}<0.05$. To verify homogeneity in the researched samples, the Shapiro-Wilk test was performed.

\section{Results}

The variables investigated in this study were: surgery side, age, number of dirty compresses, weight of dirty compresses (in grams), preoperative collector (in $\mathrm{ml}$ ), blood in the compress (in $\mathrm{ml}$ ), preoperative bleeding (in $\mathrm{ml}$ ), postoperative bleeding (in $\mathrm{ml}$ ) and total bleeding (in $\mathrm{ml}$ ).

\section{Exploratory Analysis (Tables 1-3)}

Based on the data above, the distributions of the variables were similar. Viewing this same data in the form of boxplots, in Figure 1 , both sides had a similar distribution of bleeding, generating an indication that there is no difference in bleeding between the operated sides excluding the use of the medicine (Figure 1). We observed that the test group on both sides operated on had less bleeding than the control group (Figure 2). 
Table 1: Summary measures of control group variables.

\begin{tabular}{|c|c|c|c|c|c|c|}
\hline Variables & Mínimum & Q1 & Median & Average & Q3 & Maximum \\
\hline Age & 53,0 & 55,0 & 59,0 & 58,4 & 61,0 & 63,0 \\
\hline Quantity of soiled compresses & 10,0 & 20,5 & 23,0 & 22,1 & 24,0 & 30,0 \\
\hline Weight of dirty compresses & 414,0 & 667,0 & 710,0 & 763,7 & 926,0 & 1028,0 \\
\hline Collector & 80,0 & 200,0 & 320,0 & 295,0 & 400,0 & 500,0 \\
\hline Blood in the compress & 84,0 & 129,0 & 173,0 & 206,1 & 264,0 & 428,0 \\
\hline Bleeding per & 164,0 & 399,0 & 503,0 & 502,0 & 631,0 & 726,0 \\
\hline Post bleeding & 640,0 & 735,0 & 840,0 & 904,7 & 1010,0 & 1350,0 \\
\hline Total bleeding & 1064,0 & 1191,0 & 1359,0 & 1407,0 & 1594,0 & 1898,0 \\
\hline
\end{tabular}

Table 2: Summary measures of the variables in the Test group.

\begin{tabular}{|c|c|c|c|c|c|c|}
\hline Variables & Minimum & Q1 & Median & Average & Q3 & Maximum \\
\hline Age & 53,0 & 53,3 & 56,5 & 57,0 & 59,8 & 63,0 \\
\hline Quantity of soiled compresses & 9,0 & 14,0 & 19,0 & 19,1 & 24,0 & 35,0 \\
\hline Weight of dirty compresses & 277,0 & 547,0 & 652,0 & 656,0 & 724,5 & 1092,0 \\
\hline Collector & 25,0 & 72,5 & 120,0 & 146,6 & 205,0 & 400,0 \\
\hline Blood in the compress & 79,0 & 160,5 & 205,0 & 235,7 & 306,0 & 465,0 \\
\hline Bleeding per & 174,0 & 265,5 & 358,0 & 381,7 & 461,0 & 865,0 \\
\hline Post bleeding & 320,0 & 571,5 & 670,0 & 708,8 & 900,0 & 1250,0 \\
\hline Total bleeding & 633,0 & 951,5 & 1023,0 & 1090,0 & 1194,5 & 1630,0 \\
\hline
\end{tabular}

Table 3: Summary measures of Total Bleeding per operated side.

\begin{tabular}{|c|c|c|c|c|c|}
\hline Groups & Minimum & Q1 & Median & Average & Q3 \\
\hline Right Side & 854,0 & 1084,0 & 1244,0 & 1272,0 & 1475,0 \\
\hline Left Side & 633,0 & 997,5 & 1143,0 & 1233,5 & 808,0 \\
\hline
\end{tabular}

Figure 1: Total bleeding per operated side. 


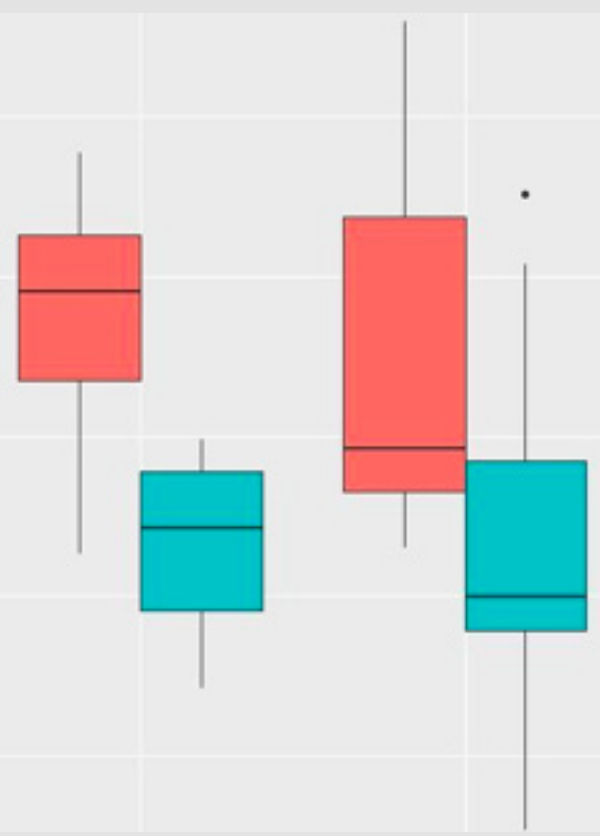

Figure 2: Total bleeding per side Operated according to treatment groups.

For the age analysis, we created the Age Range variable from the median age. We obtained a median of 59 and two new options for a new variable created: "Age group from 59 years old" and "Age group below 59 years". Analogously to the analysis of the operated sides, we observed that the Age Group variable has differences in distributions between the Age Group classes (Table 4) and (Figure 3 ). The older group had greater total bleeding than the younger group (Figure 3 \& Table 5).

Figure 3: Total Bleeding by Age Group

Table 4: Summary measures of the variable Total Bleeding according to Age category.

\begin{tabular}{|c|c|c|c|c|c|}
\hline Variables & Minimum & Q1 & Median & Average & Q3 \\
\hline$>59$ years & 953,0 & 1194,0 & 1402,0 & 1407,0 & 1593,0 \\
\hline$<59$ years & 633,0 & 957,0 & 1074,0 & 1111,0 & 1202,0 \\
\hline
\end{tabular}


Table 5: Summary measures of the Total bleeding variable by age group according to treatment group.

\begin{tabular}{|c|c|c|c|c|c|c|}
\hline Groups & Minimum & Q1 & Median & Average & Q3 & Maximum \\
\hline Control (From 59 years old) & 1183,0 & 1334,0 & 1516,0 & 1523,0 & 1674,0 & 1898,0 \\
\hline Control (Under 59) & 953,0 & 1104,0 & 1111,0 & 1174,0 & 1212,0 & 1519,0 \\
\hline Test (From 59 years old) & 1064,0 & 1102,0 & 1143,0 & 1207,0 & 1234,0 & 1574,0 \\
\hline Test (Under 59) & 633,0 & 913,0 & 968,0 & 1054,8 & 1189,8 & 1630,0 \\
\hline
\end{tabular}

We found that again the groups in which the drug was tested were those that obtained lower medians compared to their peers in the Control Group (Figure 4).

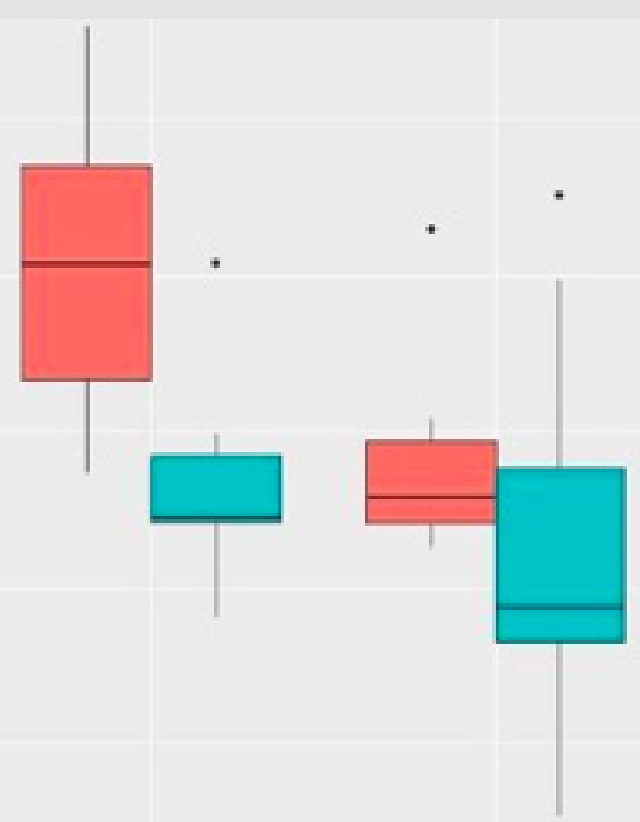

Figure 4: Boxplots of the Total bleeding variable by Age according to treatment group.

Evaluating only the differences in the total bleeding variable between treatments, that is, between the Control group and the Test group, the Test group had a lower amount of total bleeding when compared to the Control group. Table 6 shows the summary measures of these two groups (Table 6). The Figure 5 representing the measures in Table 6.

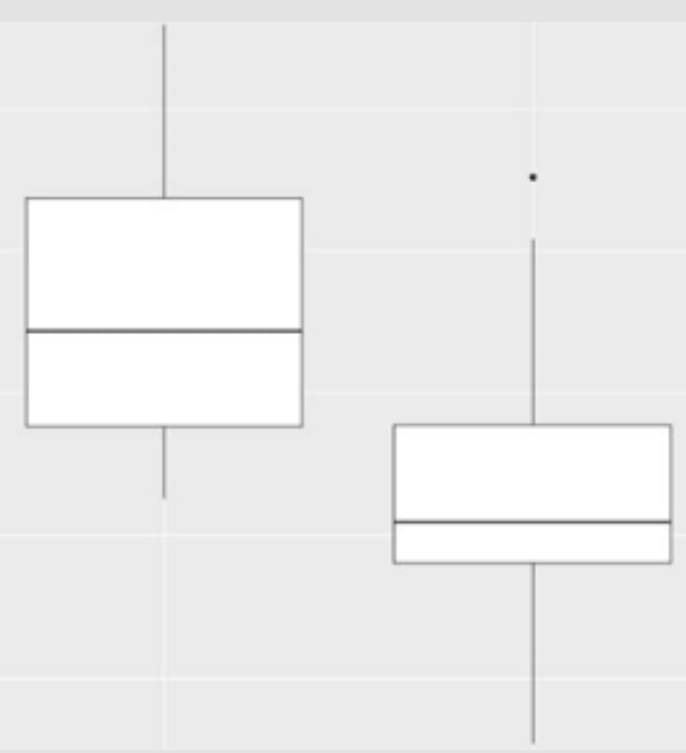

Figure 5: Total Bleeding by Treatment used. 
Table 6: Summary measures of Total Bleeding per treatment.

\begin{tabular}{|c|c|c|c|c|c|c|}
\hline Groups & Minimum & Q1 & Median & Average & Q3 & Maximum \\
\hline Control & 1064,0 & 1191,0 & 1359,0 & 1407,0 & 1594,0 & 1898,0 \\
\hline Test & 633,0 & 951,5 & 1023,0 & 1090,0 & 1194,5 & 1630,0 \\
\hline
\end{tabular}

\section{Statistical Tests}

Table 7: Student's T test result for comparisons of means of the response variables of the Control group versus Test group (Table 7).

We note that the variables Weight of Dirty Compresses, Collector and Per Bleeding, Post Bleeding and Total Bleeding showed statistically significant values, that is, at the $5 \%$ level of significance, they rejected the hypothesis that the means of the Control and Test groups were the same. With this we can affirm that at the level of $5 \%$ of significance, the drug Transamin had an effect in reducing the variables that represented the bleeding of the patients with the exception of the variable Quantity of Dirty Compresses. The Blood Bag variable, which represented the amount of blood transfused to the patient, had an expected response, where a patient who loses more blood needs more transfusion, increasing the average amount of blood received. In the database, the Control group presented 5 patients who used a blood bag obtaining an average of Total Bleeding of $1753.4 \mathrm{ml}$ and needing an average of 1.6 blood bags. In the Test group only one patient who had $1491 \mathrm{ml}$ Total Bleeding needed a blood bag.

Table 7: T-statistic and P-value of Student's T test according to variables.

\begin{tabular}{|c|c|c|}
\hline Variable & Estatistic T & p-value \\
\hline Dirty Compresses & 1,7819 & $0,04171^{*}$ \\
\hline $\begin{array}{c}\text { Quantity of Dirty } \\
\text { Compresses }\end{array}$ & 1,6392 & 0,0554 \\
\hline Collector & 4,1138 & $0,0001^{*}$ \\
\hline Bleeding Per & 2,2259 & $0,0163^{*}$ \\
\hline Post Bleeding & 2,6689 & $0,0067^{*}$ \\
\hline Total Bleeding & 3,7858 & $0,0003^{*}$ \\
\hline
\end{tabular}

*statistically significant value at the 5\% level.

\section{Discussion}

Approximately 450 thousand total knee arthroplasties are performed annually in the United States [11]. Each year we will have an increase in the number of TKA due to improvements in techniques, good results and increased life expectancy [12]. An estimate made by Kurtz et al. [13] shows a substantial increase in the number of TKA performed annually in the United States, approximately $670 \%$ increase in the year 2030 . This gives us an approximate total of 3.5 million knee arthroplasties that same year. Other important data are the large blood loss from the TKA procedure [2,3] and the high rate of blood transfusion resulting from this loss [14]. Based on these data, we were able to predict the size of the economic impact arising from hospital costs.
Considering that in the United States the average cost of a red blood cell concentrate is approximately 158 times greater than just one ampoule of tranexamic acid [14,15], the positive effect in reducing bleeding in a TKA using ATX would bring considerable savings to the system of health. With surgical trauma, an activation of the fibrinolytic system occurs at the expense of the release of tissue plasminogen activator (T-PA).

The main enzyme that acts in the conversion of plasminogen to plasmin is T-PA. In association, thrombin is also responsible for releasing T-PA in the vascular endothelium, activating fibrinolysis [16]. During surgery there is an increase in fibrinolysis due to greater release of plasmin at the site of vascular damage, caused by surgical stress. Resulting in increased blood loss. Based on this knowledge, the use of tranexamic acid (synthetic inhibitor of fibrinolysis) acts by making a competitive inhibition of plasminogen activation receptors in plasmin $[17,18]$, and due to the non-formation of plasmin, we achieve a delay in fibrinolysis which results in a clot stabilization [19]. The choice of this drug for the study was based on its safety profile and on its effectiveness reported in the literature. Even after several authors have studied the effect of using tranexamic acid in order to reduce bleeding and the need for transfusion of blood products in primary TKA, we still have disagreements regarding the dose and ideal time for the administration of the drug in studies $[20,21]$.

In the present study, we observed that there was no difference in bleeding when comparing the operated side. Our results showed that the group that used ATX had a lower mean of perioperative bleeding. Other studies have analyzed this relationship and obtained similar results $[22,23]$. No complications related to the use of the drug were observed. The Blood Bag variable was proportional to the patient who lost more blood. Analyzing the Age Group variable that was created from the median of ages, we observed that the older group had greater total bleeding than the younger group, but this finding will not be explored by this study. The variables Weight of Dirty Compresses, Collector and Pre Bleeding, Post Bleeding and Total Bleeding showed statistically significant values and with this we can say that the drug Transamin had an effect in reducing the variables that represented the bleeding of patients with the exception of the variable Quantity of Dirty Compresses.

\section{Conclusion}

We concluded that intravenous ATX applied at a dose of 20mg / $\mathrm{kg}$ after anesthetic induction was effective in satisfactorily reducing blood losses resulting from TKA surgery, which consequently resulted in a reduction in the need for blood transfusion. 


\section{References}

1. Chepurnov SA, Chepurnova NE (1981) Almond-shaped brain complex. M Publishing house, Mosk University, Morocco, pp. 256.

2. Post St, Mai JK (1980) Contribution to the amygola loid projection field in the rat. A quatitative autoradiographic study. J Hirnforsch 21(2): 199225.

3. Sapronov NS (1998) Pharmacology of the hypophyseal-adrenal system. Publishing house "Special. literature ", St. Petersburg. p. 336

4. Fujimori B, Yokota T, Ishibashi Y, Takei T (1958) Analysis of the electroencephalogram of cjildren by histoqram method. EEG and Clin Neurophysiol 10(2): 241-252.

5. Kitchigina VF (2006) Regulation mechanisms and functional significance of theta oscillations in the septohippocampal system of the brain Abstract of dissertation for the degree of Doctor of Biological Sciences, Moscow, Pushchino.

ISSN: 2574-1241

DOI: $10.26717 / B J S T R .2020 .29 .004861$

Max Rogério Freitas Ramos. Biomed J Sci \& Tech Res

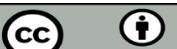

This work is licensed under Creative Commons Attribution 4.0 License

Submission Link: https://biomedres.us/submit-manuscript.php
6. Kitchigina V, Popova I, Sinelnikova V, Malkov A, Astasheva E, et al. (2013) Disturbances of septohippocampal theta oscillations in the epileptic brain: Reasons and consequences. Experimental Neurology 247: 314 327.

7. Steriade M (1996) Arousal: revisiting the reticular activating system. Sciense 272(5259): 225-226.

8. Vertes RP (1992) PHA-L analysis of projections from in the supramammillary nucleus in the rat. J Comp Neurology 326(4): 595-620.

9. Olmos JS De, Ingram VR (1972) The projection field of the stria terminals in the rat brain. An experimantal study. J Compar neurol 146(3): 303315

$\begin{array}{ll}\text { BIOMEDICAL } & \text { Assets of Publishing with us } \\ \text { RESEARCHES } & \text { - Global archiving of articles } \\ \text { - Immediate, unrestricted online access } & \text { - Rigorous Peer Review Process } \\ & \text { - Authors Retain Copyrights }\end{array}$

